\title{
Impaired Degradation of Leukotrienes in Patients with Peroxisome Deficiency Disorders
}

\author{
Ertan Mayatepek, * Wolf-Dieter Lehmann, * Joachim Fauler, ${ }^{\star}$ Dimitrios Tsikas, ${ }^{*}$ Jürgen C. Frölich, ${ }^{*}$ \\ Ruud B. H. Schutgens, ${ }^{3}$ Ronald J. A. Wanders, ${ }^{5}$ and Dietrich Keppler* \\ ${ }^{*}$ German Cancer Research Center, D-6900 Heidelberg, Federal Republic of Germany; ${ }^{\ddagger}$ Department of Clinical Pharmacology, \\ Hannover Medical School, D-3000 Hannover, Federal Republic of Germany; and ${ }^{\S}$ Department of Pediatrics, \\ University Hospital Amsterdam, 1105 AZ Amsterdam, The Netherlands
}

\begin{abstract}
The degradation of leukotrienes by $\beta$-oxidation from the $\omega$-end proceeds in peroxisomes (Jedlitschky et al. J. Biol. Chem. 1991. 266:24763-24772). Peroxisomal degradation of leukotrienes was studied in humans by analyses of endogenous leukotrienes in urines from eight patients with biochemically established peroxisome deficiency disorder and eight age- and sex-matched healthy infant controls. Leukotriene metabolites were separated by high-performance liquid chromatography, quantified by radioimmunoassays, and identified as well as quantified by gas chromatography-mass spectrometry.

Urinary leukotriene $\mathrm{E}_{4}\left(\mathrm{LTE}_{4}\right)$ and $\mathrm{N}$-acetyl-LTE $\mathrm{TH}_{4}$ excretions, relative to creatinine, were increased $>10$-fold in the patients in comparison to healthy infants. The $\beta$-oxidation product $\omega$-carboxy-tetranor- $\mathrm{LTE}_{3}$ averaged $0.05 \mu \mathrm{mol} / \mathrm{mol}$ creatinine in the controls but was not detectable in the patients. However, $\omega$-carboxy- $\mathrm{LTE}_{4}$ (median $13.6 \mu \mathrm{mol} / \mathrm{mol}$ creatinine) was significantly increased in the patients' urine, whereas $\mathbf{L T B}_{4}$ (median $0.07 \mu \mathrm{mol} / \mathrm{mol}$ creatinine) and $\omega$-carboxy-LTB L $_{4}$ were detected exclusively in the urines of the patients. These data indicate an impairment of the inactivation and degradation of both $\mathrm{LTE}_{4}$ and $\mathrm{LTB}_{4}$ in patients with peroxisomal deficiency.

The increased levels of the biologically active, proinflammatory mediators $\mathrm{LTE}_{4}$ and $\mathrm{LTB}_{4}$ might be of pathophysiological significance in peroxisome deficiency disorders. This is the first and so far only condition with a pronounced urinary excre-

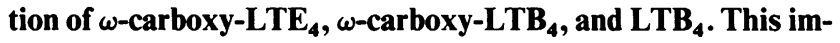
paired catabolism of leukotrienes and the altered pattern of metabolites may be of diagnostic value. These findings underline the essential role of peroxisomes in the catabolism of leukotrienes in humans. ( $J$. Clin. Invest. 1993. 91:881-888.) Key words: leukotriene analysis $\bullet \beta$-oxidation $\bullet$ peroxisomes $\bullet$ urinary leukotrienes $\bullet$ Zellweger syndrome
\end{abstract}

\section{Introduction}

Leukotrienes (LTs) ${ }^{1}$ are potent lipid mediators derived from arachidonate in the 5-lipoxygenase pathway (1-4). LTB $_{4}$ is

Address reprint requests to Dr. Dietrich Keppler, Tumor Biochemistry Division, German Cancer Research Center, Im Neuenheimer Feld 280, D-6900 Heidelberg, Federal Republic of Germany.

Received for publication 10 March 1992 and in revised form 18 August 1992.

1. Abbreviations used in this paper: BSTFA, $N, O$-Bis(trimethylsilyl)trifluoroacetamide; CAD, collision-activated dissociation; $\mathrm{CI}$,

J. Clin. Invest.

(C) The American Society for Clinical Investigation, Inc.

0021-9738/93/03/0881/08 $\$ 2.00$

Volume 91, March 1993, 881-888 chemotactically active $(5)$, whereas the cysteinyl leukotrienes, $\mathrm{LTC}_{4}, \mathrm{LTD}_{4}$, and $\mathrm{LTE}_{4}$, increase microvascular permeability and induce smooth muscle contraction (1-4). In view of the role of LTs under various pathophysiological conditions (6), their metabolic inactivation and degradation is of major interest (7). $\mathrm{LTC}_{4}$ and $\mathrm{LTD}_{4}$ are rapidly metabolized in the blood circulation to $\mathrm{LTE}_{4}(7-9)$. The liver represents the main organ for the uptake, metabolic inactivation, and biliary elimination of LTs and their metabolites (10-13). The metabolic inactivation of LTs is mediated by $\omega$-oxidation and subsequent $\beta$-oxidation from the $\omega$-end of $\mathrm{LTB}_{4}(14-16), \mathrm{LTE}_{4}$, and $N$-acetyl$\mathrm{LTE}_{4}(17-21)$. Administration of radiolabeled $\mathrm{LTC}_{4}$ and $\mathrm{LTE}_{4}$ in human subjects leads to $\omega$ - and $\beta$-oxidation products which are excreted into bile and urine (22-24). After intravenous administration of $\left[{ }^{3} \mathrm{H}\right] \mathrm{LTC}_{4}$ in the human and monkey $\left[{ }^{3} \mathrm{H}\right]-$ $\mathrm{LTE}_{4}$ is the main urinary metabolite $(22,23,25,26)$, whereas $\left[{ }^{3} \mathrm{H}\right] \mathrm{LTB}_{4}$ was not detectable in urine after intravenous $\left[{ }^{3} \mathrm{H}\right]-$ $\mathrm{LTB}_{4}(27)$. Urinary $\mathrm{LTE}_{4}$ has been proposed and used as the index metabolite for the systemic generation of cysteinyl LTs in humans (28-32).

The metabolism of $\mathrm{LTE}_{4}$ and its compartmentation are summarized in Fig. 1.

The recognition that peroxisomes have a variety of physiological functions, together with the demonstration that they are absent or deficient in certain genetic diseases (33), has led to the identification of a group of peroxisome deficiency disorders, with the Zellweger (cerebrohepatorenal) syndrome as a well-defined example $(34,35)$. Clinically, the syndrome is associated with typical dysmorphic features, failure to thrive, hepatomegaly, renal cortical cysts, severe hypotonia, epileptic seizures, psychomotoric retardation, and premature death within the first year of life (36). Multiple peroxisomal biochemical processes are defective including $\beta$-oxidation of very long chain fatty acids (VLCFAs) (37), phytanic acid oxidation $(38,39)$, pipecolic acid oxidation (40), and plasmalogen (41) and bile acid $(42,43)$ biosynthesis.

Peroxisomes were recently identified as the site of LT $\beta$-oxidation from the $\omega$-end (44) (Fig. 1). Whereas the cysteinyl LT $\omega$-carboxy- $N$-acetyl- $\mathrm{LTE}_{4}$ was exclusively $\beta$-oxidized in peroxisomes, $\omega$-carboxy- $\mathrm{LTB}_{4}$ was degraded both in isolated peroxisomes and mitochondria (44). Patients with disorders of peroxisome biogenesis offer a unique possibility to study the im-

chemical ionization mass spectrometry; ECL, equivalent carbon chain length; GC-MS-MS, gas chromatography-mass spectrometry-mass spectrometry; HTMP, 4-hydroxy-2,2,6,6-tetramethylpiperidine$N(1)$-oxyl; LT, leukotriene; MID, multiple ion detection; OTMS, trimethylsilyloxy; $\mathbf{P}^{-}$, parent ion; $\mathrm{PFB}$, pentafluorobenzyl; RIA, radioimmunoassay; RP-HPLC, reversed-phase high-performance liquid chromatography; TMS, trimethylsilyl; TMSOH, trimethylsilanol; VLCFAs, very long chain fatty acids. 


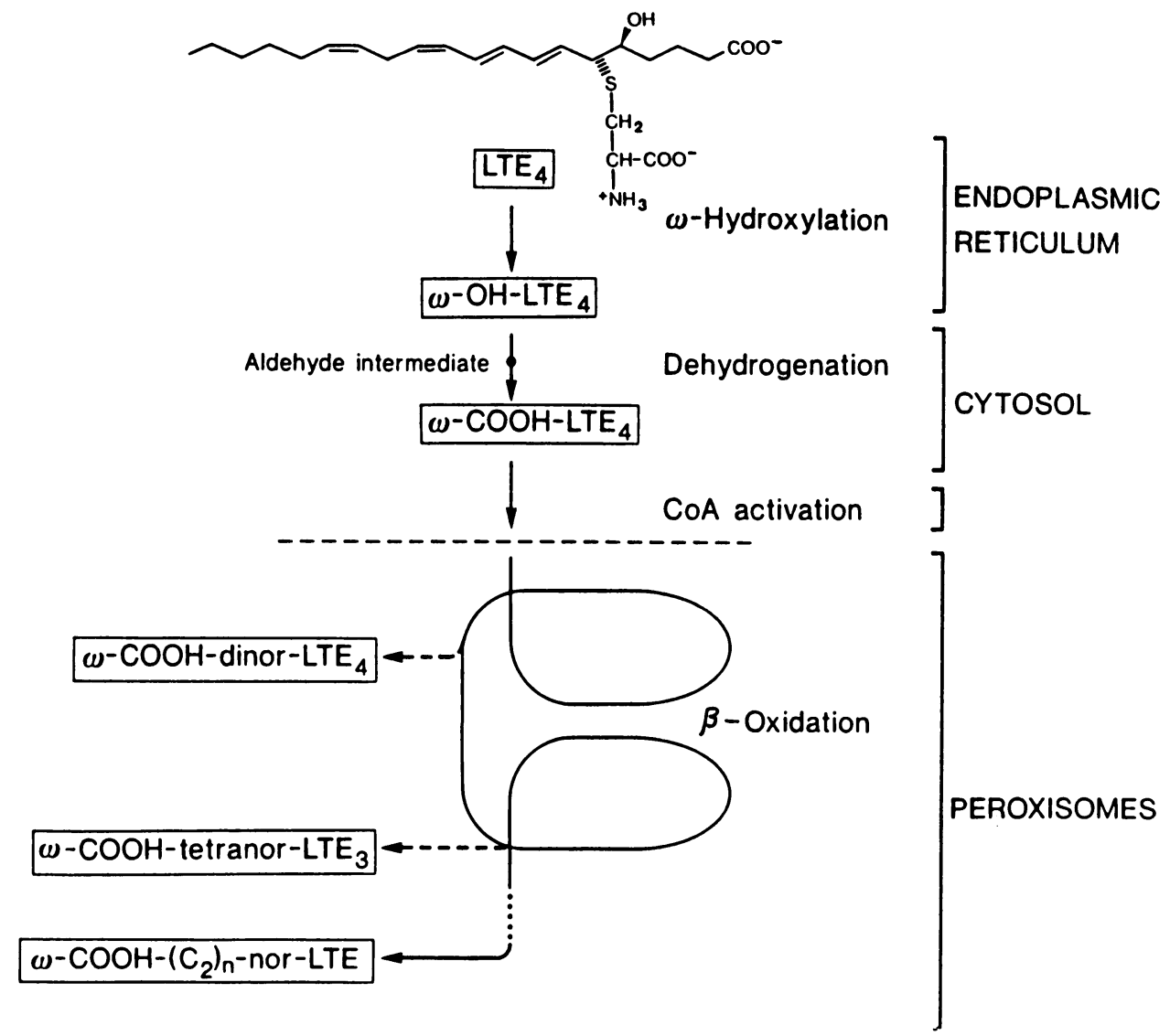

Figure 1. Structure of $\mathrm{LTE}_{4}$, its degradation by $\omega$-oxidation and subsequent $\beta$-oxidation, and the compartmentation of this pathway. $\omega$-Hydroxylation of $\mathrm{LTE}_{4}$ is catalyzed by microsomal $\mathrm{LTE}_{4}{ }^{-}$ 20-monooxygenase (EC 1.14.13.14) (17) followed, particularly in hepatocytes, by two dehydrogenase-catalyzed reactions leading to $\omega$-carboxy- $\mathrm{LTE}_{4}(\omega$ $\left.\mathrm{COOH}-\mathrm{LTE}_{4}\right)(64)$; the $\omega$-aldehyde intermediate is indicated. After activation at the $\omega$-end by an acyl-CoA-synthetase, several peroxisomal $\beta$-oxidation cycles lead to a stepwise degradation of the LT from the $\omega$-end (44). $\omega$ Carboxy- $\left(\mathrm{C}_{2}\right)_{\mathrm{n}}$-nor-LTE indicates $\omega$-carboxy- $\mathrm{LTE}_{4}$ catabolites with $<16$ carbon atoms in the dicarboxylate chain. $\mathrm{LTB}_{4}$ is $\omega$-oxidized and degraded by $\beta$-oxidation in reactions which are analogous $(44$, $65)$. The horizontal dashed line indicates the block in this degradation pathway in peroxisome deficiency disorders. portance of peroxisomes in LT degradation in vivo. Since leukotrienes can be analyzed in human urine, it was the aim of this study to investigate the pattern of LT metabolites in urines from patients with peroxisome deficiency disorders. We demonstrate for the first time that these patients exhibit an impaired degradation and inactivation of cysteinyl LTs as well as $\mathrm{LTB}_{4}$. These results may be of diagnostic value and possibly of pathophysiological interest.

\section{Methods}

Patients. Endogenous LT metabolite excretion was studied in eight patients with a peroxisome deficiency (Zellweger syndrome) and eight age- and sex-matched healthy infants. All patients exhibited the characteristic cranofacial and ocular abnormalities described for Zellweger syndrome (36). Convulsions were reported in all patients. There were no signs of cholestasis, liver failure, or impaired renal function. The diagnosis was established by specific biochemical analyses as described below.

Biochemical analyses for diagnosis. VLCFAs $\left(>\mathrm{C}_{22}\right)$ in plasma and fibroblasts (45) as well as plasma bile acid intermediates (46) were determined by gas chromatography. De novo plasmalogen biosynthesis in cultured fibroblasts was analyzed as described (47).

Chemicals. 4-Hydroxy-2,2,6,6-tetramethylpiperidine- $N(1)$-oxyl (HTMP), N,N-diisopropylethylamine, and butyryl cholinesterase (from horse serum, 500-1,000 U/mg) were obtained from Sigma Chemical Co., St. Louis, MO. LTC 4 , LTD $_{4}, \mathrm{LTE}_{4}, \mathrm{LTB}_{4}, \omega$-carboxy$\mathrm{LTB}_{4}$, and $\omega$-carboxy-LTE $\mathrm{L}_{4}$ were purchased from Cascade Biochem. Ltd., University of Reading, UK. $\left[{ }^{3} \mathrm{H}\right] \mathrm{LTC}_{4}(4.8 \mathrm{TBq} / \mathrm{mmol}),\left[{ }^{3} \mathrm{H}\right]-$ $\operatorname{LTD}_{4}(1.5 \mathrm{TBq} / \mathrm{mmol}),\left[{ }^{3} \mathrm{H}\right] \mathrm{LTE}_{4}(4.8 \mathrm{TBq} / \mathrm{mmol})$, and $\left[{ }^{3} \mathrm{H}\right] \mathrm{LTB}_{4}$ (7.0 TBq/ mmol) were from Du Pont-New England Nuclear, Boston, MA. ${ }^{18} \mathrm{O}$-labeled water $\left(95\right.$ at $\left.\%{ }^{18} \mathrm{O}\right)$ was from Preusser Chemie, Jülich, FRG. 2,3,4,5,6-Pentafluorobenzylbromide (PFB bromide) was ob- tained from Aldrich Chemical Co., Steinheim, FRG. N,O-Bis(trimethylsilyl)trifluoroacetamide (BSTFA) $+1 \%$ trimethyl-chlorosilane was from Pierce Chemical Co., Rockford, IL. Rhodium (5\% on activated alumina) was obtained from Fluka Chemie, Buchs, Switzerland.

Urine collection and leukotriene extraction. Urine was obtained either from spontaneous micturition or was collected from a catheter introduced into the urinary bladder. Immediately after collection, portions of urine were mixed with $2 \mathrm{vol}$ of $90 \%$ ( $\mathrm{vol} / \mathrm{vol}$ ) aqueous methanol of $\mathrm{pH} 8.5$ containing $0.5 \mathrm{mM}$ EDTA, $1 \mathrm{mM}$ HTMP, and $20 \mathrm{mM}$ $\mathrm{KHCO}_{3}$, and stored at $-80^{\circ} \mathrm{C}$ under argon (31). Directly before analysis, the samples were brought to room temperature and the appropriate internal standards ( see below) were added. The samples were acidified to $\mathrm{pH} 4.5$ by addition of $0.1 \mathrm{M} \mathrm{HCl}$, mixed, and pumped slowly through activated Sep-Pak $\mathrm{C}_{18}$ cartridges (Waters Associates, Milford, MA). The cartridges were washed with $50 \mathrm{ml}$ of distilled $\mathrm{H}_{2} \mathrm{O}$ and LTs were eluted with $5 \mathrm{ml}$ of $90 \%$ aqueous methanol containing $1 \mathrm{mM}$ HTMP and $0.5 \mathrm{mM}$ EDTA. The eluates were evaporated to dryness under reduced pressure and resuspended in $30 \%$ ice-cold aqueous methanol (23).

An aliquot of each urine sample was screened (Combur ${ }^{9}$ test, Boehringer Mannheim GmbH, Mannheim, FRG) to exclude the presence of pathological amounts of leukocytes, erythrocytes, and protein.

Reversed-phase high-performance liquid chromatography (RP$H P L C)$. Fractions containing distinct LTs were obtained by RP-HPLC on $\mathrm{a}_{18}$ Hypersil column $(4.6 \times 250 \mathrm{~mm}, 5-\mu \mathrm{m}$ particle size; Shandon, Runcorn, UK). Fractions containing $\mathrm{LTC}_{4}, \mathrm{LTD}_{4}, \mathrm{LTE}_{4}$, and $N$-acetyl-LTE ${ }_{4}$ were prepared by RP-HPLC using as mobile phase methanol/ water $(65: 35, \mathrm{vol} / \mathrm{vol})$ the aqueous part containing $0.1 \%$ acetic acid, 1 mM EDTA, and being adjusted to $\mathrm{pH} 5.6$ by ammonium hydroxide (23). $\mathrm{LTB}_{4}$ fractions were also prepared isocratically with an acetonitrile/water (38:62, vol/vol) system, the aqueous part showing the identical composition as described above. $\omega$-Carboxy-tetranor- $\mathrm{LTE}_{3}$, $\omega$-carboxy- $-\mathrm{LTE}_{4}$, and $\omega$-carboxy- $\mathrm{LTB}_{4}$ were purified by a linear gradient of $0-80 \%$ methanol, $0.1 \%$ acetic acid, $\mathrm{pH}$ 5.0. For all separations, 
a flow rate of $1 \mathrm{ml} / \mathrm{min}$ was used. For identification by its ultraviolet (UV) spectrum (see Fig. 2), $\omega$-carboxy-LTE $\mathrm{L}_{4}$ was further purified by isocratic RP-HPLC using mobile phase methanol/water (52:48, vol/ vol), containing $0.1 \%$ acetic acid, $1 \mathrm{mM}$ EDTA, and adjusted to $\mathrm{pH}$ 5.0 with ammonium hydroxide (23). UV spectra were recorded online using a photodiode array detector type 990 (Waters Associates).

Preparation of ${ }^{3} \mathrm{H}$-labeled analogues as internal standards for radioimmunoassays (RIAs). ${ }^{3} \mathrm{H}$-labeled LTs were used as internal standards in the extraction/RP-HPLC/RIA procedure to correct for recovery losses and as competitive antigens in the RIA procedures. Not commercially available ${ }^{3} \mathrm{H}$-analogues were prepared as follows: $N$-acetyl$\left[{ }^{3} \mathrm{H}\right] \mathrm{LTE}_{4}$ was synthesized from $\left[{ }^{3} \mathrm{H}\right] \mathrm{LTE}_{4}$ as described previously (48). The product was purified by RP-HPLC. $\omega$-Carboxy-tetranor$\left[{ }^{3} \mathrm{H}_{\mathrm{LTE}_{3}}\right.$ was prepared by injecting $N$-acetyl- $[5,6,8,9,11,12,14,15$ ${ }^{3} \mathrm{H}_{8} \mathrm{LTE}_{4}$ intravenously into anaesthetized and bile duct-cannulated rats. Bile was collected continuously into ice-cold $90 \%$ aqueous methanol containing $1 \mathrm{mM}$ HTMP and $0.5 \mathrm{mM}$ EDTA, and aliquots were counted for radioactivity. Bile samples were evaporated to dryness and redissolved in 30\% methanol. Separation of $\omega$-carboxy-tetranor- $N$ acetyl- $\left[{ }^{3} \mathrm{H}\right] \mathrm{LTE}_{3}$ was performed as described $(44)$. Enzymatic deacetylation of this product to $\omega$-carboxy-tetranor- $\left[{ }^{3} \mathrm{H}\right] \mathrm{LTE}_{3}$ was performed by penicillin amidase ( 48 ) and the product was identified by co-chromatography with the synthetic standard $(23,44)$.

$R I A s$. For LT analysis by RIA, 20-ml aliquots of urine were spiked with 3,500 dpm each of the corresponding ${ }^{3} \mathrm{H}$-labeled LTs. The RPHPLC eluate was collected in $1-\mathrm{ml}$ fractions, of which $300 \mu \mathrm{l}$ was counted for calculation of the ${ }^{3} \mathrm{H}$ recovery and $700 \mu \mathrm{l}$ was dried for the subsequent RIAs. These were performed as described $(26,49)$. Data were corrected for the recovery of the ${ }^{3} \mathrm{H}$-labeled LTs added as internal standards. The lower detection limit for LTs was about $50 \mathrm{fmol}$. The monoclonal cysteinyl LT antibody was kindly donated by Dr. F. Kohen, The Weizmann Institute of Science (Rehovot, Israel). The molar crossreactivities at $50 \%$ binding of $\mathrm{LTE}_{4}, \mathrm{~N}$-acetyl-LTE $\mathrm{LTD}_{4}$, and $\mathrm{LTC}_{4}$ were $100 \%, 140 \%, 160 \%$, and $210 \%$, respectively. The $\mathrm{LTB}_{4}$ antibody was kindly provided by Dr. A. W. Ford-Hutchinson (Merck Frosst, Pointe-Claire/Dorval, Quebec, Canada). Its molar cross-reactivities at $50 \%$ binding were as follows: $\mathrm{LTB}_{4}, 100 \%$; cysteinyl LTs including $12(\mathrm{~S})$-hydroxyeicosatetraenoate, $<0.05 \% ; 6$-trans- $\mathrm{LTB}_{4}$, $2.0 \%$; 6-trans-12-epi-LTB ${ }_{4}, 0.6 \% ; 20$-hydroxy-LTB ${ }_{4}, 1.0 \%$; $\omega$-carboxy$\mathrm{LTB}_{\mathbf{4}}, 1.0 \%$ (data provided by Merck Frosst, Canada). Antisera to $\omega$-carboxy-tetranor-LTE $\mathrm{L}_{3}$ were kindly provided by Dr. P. Tagari (Merck Frosst, Canada) and were purified from pooled sera of immunized rabbits as described (50).

Preparation of ${ }^{18} \mathrm{O}$-labeled $\omega$-carboxy- $L T E_{4}$ as internal standard for gas chromatography-mass spectrometry (GC-MS). $20 \mu \mathrm{g}$ of synthetic $\omega$-carboxy-LTE $\mathrm{LT}_{4}$ was incubated with $500 \mu \mathrm{l}$ of $\mathrm{H}_{2}{ }^{18} \mathrm{O}$ for $12 \mathrm{~h}$ at $25^{\circ} \mathrm{C}$ in the presence of $300 \mathrm{U}$ of butyryl cholinesterase. The incubation mixture was acidified to $\mathrm{pH} 3.5$ with concentrated formic acid and extracted two times with $2 \mathrm{ml}$ of ethyl acetate. The combined extracts were taken to dryness and redissolved in a methanol/ethanol (1:1, $\mathrm{vol} / \mathrm{vol}$ ) mixture. Determination of the ${ }^{18} \mathrm{O}$-label distribution by negative ion chemical ionization mass spectrometry (CI-MS) of the hydrogenated and desulfurized pentafluorobenzyl (PFB)/trimethylsilyl (TMS) derivatives (24) revealed the following distribution: $\left[{ }^{18} \mathrm{O}_{0}\right]$ $=1.0 \%,\left[{ }^{18} \mathrm{O}_{1}\right]=12.3 \%,\left[{ }^{18} \mathrm{O}_{2}\right]=84.3 \%,\left[{ }^{18} \mathrm{O}_{3}\right]=2.4 \%$. Mass spectrometric investigations of the derivatives prepared for CI-MS by electron impact MS showed that the ${ }^{18} \mathrm{O}$ incorporation occurred at the $\omega$-end (as described in Results). The concentration of the $\left[{ }^{18} \mathrm{O}_{2}\right]-\omega$-carboxy$\mathrm{LTE}_{4}$ solution was determined by stable isotope dilution with a solution of nonlabeled $\omega$-carboxy-LTE $\mathrm{L}_{4}$, the concentration of which had been determined on the basis of its absorption at $280 \mathrm{~nm}$ and a molar absorptivity of $\epsilon=40,000 \mathrm{~cm}^{-1} \mathrm{M}^{-1}$. The recovery of $\left[{ }^{18} \mathrm{O}_{2}\right]-\omega$ carboxy-LTE $\mathrm{L}_{4}$ relative to the nonlabeled starting material was $\sim 50 \%$.

Quantification of $\omega$-carboxy-LTE $E_{4}$ by GC-MS. For the quantification of $\omega$-carboxy-LTE ${ }_{4}$ in urine, $220 \mathrm{ng}$ of $\left[{ }^{18} \mathrm{O}_{2}\right]-\omega$-carboxy-LTE $\mathrm{LT}_{4}$ were added to a $20-\mathrm{ml}$ urine sample. The sample was mixed and immediately worked up by solid-phase extraction and RP-HPLC as described above. The HPLC fractions containing endogenous urinary $\omega$-carboxy- $\mathrm{LTE}_{4}$ plus the internal standard were collected $(1.5-2 \mathrm{ml})$ and without prior concentration subjected to the desulfurization/hydrogenation procedure catalyzed by $\mathrm{Rh} / \mathrm{Al}_{2} \mathrm{O}_{3}$ to generate 5-hydroxy1,20 -eicosadioate exactly as described $(24,51)$. Then the samples were converted to their PFB esters by treatment with $100 \mu \mathrm{l}$ of a $30 \%$ PFB bromide solution in acetonitrile plus $10 \mu \mathrm{l}$ of $N, N$-diisopropylamine for $30 \mathrm{~min}$ at $30^{\circ} \mathrm{C}$. After removal of the reagents under a stream of nitrogen, the samples were incubated for $60 \mathrm{~min}$ at $60^{\circ} \mathrm{C}$ with $50 \mu \mathrm{l}$ of BSTFA to obtain the desulfurized and hydrogenated PFB/TMS derivatives. Aliquots thereof, corresponding to $1-2 \%$, were then injected into a GC-MS system and analyzed by negative ion CI-MS. The analyses were performed on a double-focusing mass spectrometer type MAT 95 (Finnigan MAT, Bremen, FRG) directly interfaced to a HP-5890 gas chromatograph (Hewlett-Packard Co., Palo Alto, CA ) equipped with a temperature-programmable injection system (KAS-2, Gerstel, Mülheim, FRG). The GC column used was a OV-1 fused silica column ( 10 -m length, 0.25-mm i.d., 0.1- $\mu \mathrm{m}$ film thickness, Macherey \& Nagel, Düren, FRG). The GC temperature program started with an isothermal step of $1 \mathrm{~min}$ at $200^{\circ} \mathrm{C}$, followed by a linear increase from 200 to $320^{\circ} \mathrm{C}$ at a rate of $15^{\circ} \mathrm{C} / \mathrm{min}$. Helium was used as carrier gas with a linear velocity of $1.4 \mathrm{~m} / \mathrm{s}$. The GC-MS interface temperature was adjusted to $280^{\circ} \mathrm{C}$ and the ion source to $220^{\circ} \mathrm{C}$. Isobutane was used as reagent gas for negative ion CI-MS. Quantifications were performed in the multiple ion detection (MID) mode, where the ion signals at $\mathrm{m} / \mathrm{z} 609.303$ and 613.312 were monitored at a mass spectrometric resolution of $\sim 2,500$.

Identification of $L T E_{4}, L T B_{4}$, and $\omega$-carboxy- $L T B_{4}$ by $G C-M S$ $M S$. Aliquots of urine were spiked with $\left[{ }^{3} \mathrm{H}\right] \mathrm{LTE}_{4},\left[{ }^{3} \mathrm{H}\right] \mathrm{LTB}_{4}$, and $\omega$-carboxy- $\left[{ }^{3} \mathrm{H}\right] \mathrm{LTB}_{4} \cdot \omega$-Carboxy- $\left[{ }^{3} \mathrm{H}\right] \mathrm{LTB}_{4}$ was prepared from $\left[{ }^{3} \mathrm{H}\right]-$ $\mathrm{LTB}_{4}$ using rat liver microsomes and cytosol $(17,52)$. The RP-HPLC fractions containing these standards were collected and evaporated under reduced pressure. The residues were redissolved in $100 \mu \mathrm{l}$ methanol and treated individually for GC-MS-MS. Endogenous and synthetic $\mathrm{LTE}_{4}$ was catalytically reduced and desulfurized to 5-hydroxy1,20-eicosadioate applying the first step of the method described by Balazy and Murphy (51). Then, the samples were reacted with PFB bromide and BSTFA as described above to obtain the PFB-ester/TMSether derivatives. $\mathrm{LTB}_{4}$ and $\omega$-carboxy- $\mathrm{LTB}_{4}$ were only reacted with PFB bromide and BSTFA. For identification, these samples were analyzed by GC-MS-MS on a triple-stage quadrupole mass spectrometer type TSQ 45 directly coupled to a gas chromatograph type 9611 (both Finnigan MAT, San Jose, CA) equipped with a fused silica OV-1 column (25-m length, 0.25-mm i.d., 0.25- $\mu \mathrm{m}$ film thickness, Macherey \& Nagel). The GC temperature program started with an isothermal step of $2 \mathrm{~min}$ at $100^{\circ} \mathrm{C}$, then the temperature was increased to $250^{\circ} \mathrm{C}$ at a rate of $25^{\circ} \mathrm{C} / \mathrm{min}$, followed by an increase to $320^{\circ} \mathrm{C}$ at a rate of $4^{\circ} \mathrm{C} /$ min. Injector, interface, and ion source were kept at $280^{\circ} \mathrm{C}, 300^{\circ} \mathrm{C}$, and $130^{\circ} \mathrm{C}$, respectively. Helium was used as GC carrier gas at a pressure of $55 \mathrm{kPa}$, and methane as reagent gas for negative ion CI. Collision-activated dissociation (CAD) was performed using argon at a pressure of $0.13 \mathrm{~Pa}$ at a collision energy of $10 \mathrm{eV}$ for $\mathrm{LTE}_{4}$ and $\mathrm{LTB}_{4}$, and $14 \mathrm{eV}$ for $\omega$-carboxy- $\mathrm{LTB}_{4}$.

Statistical analysis. Data are given as the median with the range in brackets. The Wilcoxon-Mann-Whitney test for the one-sided problem was used for statistical comparison between urinary LT metabolite concentrations from patients and normal subjects.

\section{Results}

Diagnosis of peroxisome deficiency disorder. The results of the diagnostic laboratory analyses are summarized in Table I. The VLCFA profiles in plasma were abnormal in all patients. In fibroblasts, the VLCFA profiles were abnormal in six patients; in the remaining two (patients 2 and 8 ), fibroblasts were not available. The same was observed for the de novo plasmalogen synthesis which was impaired in the six patients which could be analyzed. Abnormal intermediates of bile acid biosynthesis, 
Table I. Biochemical Findings in Patients with Peroxisome Deficiency Disorders and Healthy Infant Controls

\begin{tabular}{|c|c|c|c|c|c|c|c|}
\hline \multirow[b]{2}{*}{ Patient } & \multicolumn{3}{|c|}{ Plasma VLCFA } & \multirow{2}{*}{$\begin{array}{c}\text { Abnormal } \\
\text { bile acids } \\
\text { in plasma }\end{array}$} & \multicolumn{2}{|c|}{ Fibroblast VLCFA } & \multirow{2}{*}{$\begin{array}{c}\text { Fibroblast } \\
\text { plasmalogen } \\
\text { synthesis }\end{array}$} \\
\hline & C26:0 & C26:1 & $\mathrm{C} 26: 0 / \mathrm{C} 22: 0$ & & $\mathrm{C} 26: 0$ & $\mathrm{C} 26: 0 / \mathrm{C} 22: 0$ & \\
\hline & mg/liter & $m g / l i t e r$ & & & $\mu \mathrm{g} / \mathrm{mg}$ protein & & ${ }^{3} \mathrm{H} /{ }^{44} \mathrm{C}$ in alkenyl $\mathrm{PE}$ \\
\hline 1 & 3.88 & 3.38 & 0.56 & + & 0.52 & 1.01 & 21.0 \\
\hline 2 & 1.00 & 0.31 & 0.11 & + & 0.24 & 0.22 & 4.1 \\
\hline 3 & 2.08 & 0.81 & 0.30 & + & $\mathrm{NA}^{*}$ & NA & NA \\
\hline 4 & 2.90 & 2.22 & 0.49 & + & 0.65 & 0.62 & 43.6 \\
\hline 5 & 3.41 & 0.74 & 0.44 & + & 0.51 & 0.35 & 8.7 \\
\hline 6 & 3.61 & 0.99 & 0.18 & + & 0.33 & 0.18 & 4.9 \\
\hline 7 & 2.31 & 1.30 & 0.41 & + & 0.34 & 0.37 & 16.7 \\
\hline 8 & 1.83 & 0.45 & 0.17 & + & NA & NA & NA \\
\hline Normal & $0.31(110)$ & $<0.05(110)$ & $0.01(110)$ & - & $0.06(60)$ & $0.03(60)$ & $0.7(59)$ \\
\hline values & {$[0.11-0.62]^{\ddagger}$} & & {$[0.001-0.020]$} & & {$[0.02-0.10]$} & {$[0.02-0.05]$} & [0.4-1.5] \\
\hline
\end{tabular}

*NA, not analyzed. ${ }^{\ddagger}$ Median with the number of individuals in parentheses and the 5-90\% range in brackets.

such as $3 \alpha-, 7 \alpha-, 12 \alpha$-trihydroxy-5 5 -cholestanoic acid, were detected in the plasma of all patients.

Quantification of urinary $L T C_{4}$ and $L T D_{4} \cdot \mathrm{LTC}_{4}$ and $\mathrm{LTD}_{4}$ concentrations were below the detection limit in all urines in both groups.

Identification and quantification of urinary $\mathrm{LTE}_{4}$. Urinary concentrations of $\mathrm{LTE}_{4}$ were determined by RIA in controls and patients with peroxisome deficiency disorders as given in Table II. The median $\mathrm{LTE}_{4} /$ creatinine ratio for the patients was a factor of 11 in excess of the controls. In addition to the specificity of the RIA for $\mathrm{LTE}_{4}$, its presence was confirmed by a mass spectrometric technique. Investigation of a HPLC fraction of urinary $\mathrm{LTE}_{4}$ after derivatization to its desulfurized and hydrogenated PFB/TMS derivative by GC-MS-MS yielded a mass spectrum with the parent ion at $m / z 399$ (for [M-PFB] $]^{-}$) and two characteristic fragment ions at $m / z 309$ (for [M-PFBTMSOH] ${ }^{-}$) and $m / z 253$ (for [M-PFB- $\mathrm{CH}_{3} \mathrm{CH}_{2} \mathrm{COOTM}$ $\left.\mathrm{S}^{-}\right)$.The mass spectrum and the $\mathrm{GC}$ retention time at which it was observed were identical for urinary and synthetic $\mathrm{LTE}_{4}$.

Identification and quantification of urinary $N$-acetyl-LTE Endogenous N-acetyl-LTE 4 was quantified by RIA $(23,31)$. After enzymatic deacetylation as described above the endogenous $\mathrm{N}$-acetyl-LTE ${ }_{4}$ co-chromatographed on RP-HPLC with synthetic $\mathrm{LTE}_{4}$, thus providing additional evidence for its correct identification. As shown in Table II, the peroxisome deficiency patients showed an increased $N$-acetyl-LTE ${ }_{4} /$ creatinine ratio by a factor of 20 .

Identification and quantification of $\omega$-carboxy-LTE 4 . A sample of 11 of urine from patient 1 was concentrated in several steps by Sep-Pak $C_{18}$ solid-phase extraction and then separated in a two-step HPLC procedure as described in Methods. As displayed in Fig. 2, UV detection at $280 \mathrm{~nm}$ showed the presence of a strongly absorbing compound with a RP-HPLC retention time of $23.0 \mathrm{~min}$, being identical to the retention time of synthetic $\omega$-carboxy-LTE 4 .

Further, this compound showed the characteristic UV absorbance spectrum of a conjugated triene. Analysis of this HPLC fraction by GC-MS after derivatization into the desulfurized and hydrogenated PFB/TMS derivative gave an intense signal at $m / z 609$ at a retention time of $7 \mathrm{~min} 40 \mathrm{~s}$. Calibration of the GC separation by a set of linear fatty acid methyl esters revealed the equivalence of this retention time to an equivalent carbon chain length (ECL) of 28.45. This ECL value reasonably fits to the investigated derivative of $\omega$-carboxy-LTE ${ }_{4}$ when compared to published data of homologous compounds (24). The negative ion CI mass spectrum of the urinary $\omega$-carboxy- $\mathrm{LTE}_{4}$ derivative showed an intense signal at $m / z 609$ (for [M-PFB] ${ }^{-}$) as base peak and only a few minor

Table II. Endogenous LTs in the Urine of Normal Infants and Patients with Peroxisome Deficiency Disorders

\begin{tabular}{|c|c|c|}
\hline & $\begin{array}{l}\text { Normal } \\
\text { infants }\end{array}$ & $\begin{array}{c}\text { Peroxisome } \\
\text { deficiency }\end{array}$ \\
\hline & \multicolumn{2}{|c|}{ Concentration in urine } \\
\hline & \multicolumn{2}{|c|}{$n M$} \\
\hline $\mathrm{LTE}_{4}$ & $0.12[0.04-0.20]$ & $0.92[0.67-1.65]$ \\
\hline$N$-Acetyl-LTE 4 & $0.03[0.003-0.040]$ & $0.32[0.05-0.77]$ \\
\hline$\omega$-Carboxy-LTE ${ }_{4}$ & $0.3[0.1-1.7]$ & $16.1[3.0-62.8]$ \\
\hline$\omega$-Carboxy-tetranor- & & \\
\hline $\mathrm{LTE}_{3}$ & $0.11[0.04-0.16]$ & $<0.01$ \\
\hline \multirow[t]{3}{*}{$\mathrm{LTB}_{4}$} & $<0.01$ & $0.16[0.06-0.29]$ \\
\hline & \multicolumn{2}{|c|}{ Leukotriene/creatinine ratio } \\
\hline & \multicolumn{2}{|c|}{$\mu \mathrm{mol} / \mathrm{mol}$} \\
\hline $\mathrm{LTE}_{4}$ & $0.06[0.02-0.08]$ & $0.68[0.29-0.88]$ \\
\hline$N$-Acetyl-LTE 4 & $0.01[0.001-0.020]$ & $0.20[0.05-0.49]$ \\
\hline$\omega$-Carboxy-LTE 4 & $0.2[0.1-0.3]$ & $13.6[2.9-53.7]$ \\
\hline \multicolumn{3}{|l|}{$\omega$-Carboxy-tetranor- } \\
\hline $\mathrm{LTE}_{3}$ & $0.05[0.02-0.10]$ & $<0.005$ \\
\hline $\mathrm{LTB}_{4}$ & $<0.01$ & $0.07[0.03-0.22]$ \\
\hline
\end{tabular}

$\mathrm{LTE}_{4}, N$-acetyl-LTE,$\omega$-carboxy-tetranor-LTE $\mathrm{L}_{3}$ and $\mathrm{LTB}_{4}$ were measured by RP-HPLC and subsequent RIA; $\omega$-carboxy-LTE $\mathrm{LE}_{4}$ was identified and quantified by GC-MS, as described in Methods. Analyses were performed in the urines of eight patients and eight healthy age- and sex-matched infant controls. Data are the median with the range in brackets. Each median in patients was significantly different from the respective median in infant controls $(P<0.01)$. 


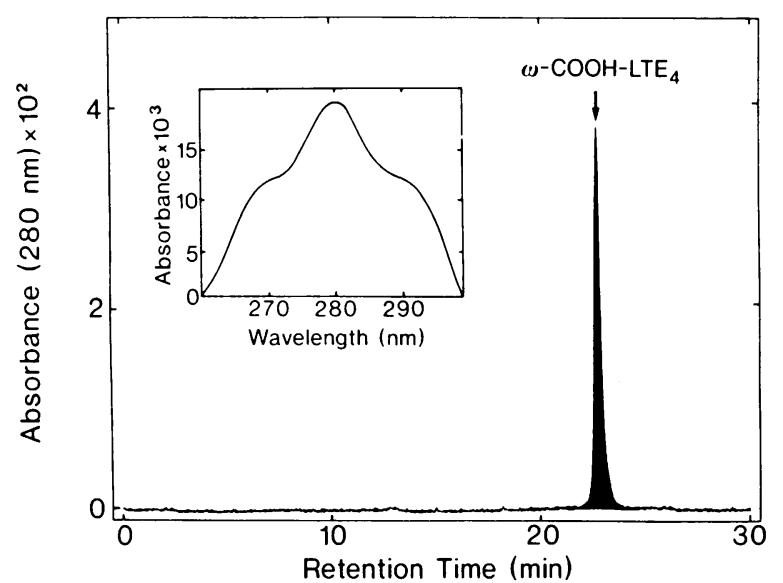

Figure 2. Detection and identification of endogenous $\omega$-carboxy-LTE $\left(\omega-\mathrm{COOH}-\mathrm{LTE}_{4}\right)$. A sample of 1 liter of urine of patient 1 with peroxisomal deficiency (Table I) was purified as described in Methods. The RP-HPLC run shown was performed with a 52\% aqueous methanol mobile phase system. The peak with the retention time of $23 \mathrm{~min}$ co-eluted with synthetic $\omega$-carboxy-LTE $\mathrm{L}_{4}$ as indicated by an arrow, and showed the characteristic UV absorbance spectrum of a conjugated triene (inset).

fragments, e.g., at $m / z 519$ (for [M-PFB-TMSOH] $]^{-}$), and at $m / z 535$ (for [M-PFB-74] ${ }^{-}$) with a relative abundance in the order of $10 \%$ of the base peak. For the $\left[{ }^{18} \mathrm{O}_{2}\right]-\omega$-carboxy-LTE $\mathrm{L}_{4}$, these signals are shifted to 613,523 , and 539 as a result of the incorporation of two atoms of ${ }^{18} \mathrm{O}$. The label distribution observed for the $\left[{ }^{18} \mathrm{O}_{2}\right]-\omega$-carboxy-LTE $\mathrm{LE}_{4}$ indicates an oxygen isotope exchange at a single carboxy group. To investigate the location of the label, the desulfurized/hydrogenated/PFB/ TMS derivatives were investigated by electron impact MS. Investigation of the derivative of nonlabeled $\omega$-carboxy-LTE gave two intense fragment ions at $m / z 369$ and 523, representing the two complementary $\alpha$-fission fragments at the OTMSgroup at C-5 that contain the carboxy group at C-1 or C-20, respectively. In the corresponding analysis of $\left[{ }^{18} \mathrm{O}_{2}\right]-\omega$-carboxy- $-\mathrm{LE}_{4}$ these characteristic fragment ions were observed at $\mathrm{m} / \mathrm{z} 369$ and 527 showing the localization of the ${ }^{18} \mathrm{O}$ label at the $\omega$-end.

The GC retention times of urinary, synthetic, and ${ }^{18} \mathrm{O}-\mathrm{la}$ beled $\omega$-carboxy- $\mathrm{LTE}_{4}$ were identical within $1 \mathrm{~s}$. Under the analytical conditions used, no back exchange of ${ }^{18} \mathrm{O}$ against ${ }^{16} \mathrm{O}$ was observed for the internal standard $\left[{ }^{18} \mathrm{O}_{2}\right]-\omega$-carboxy$\mathrm{LTE}_{4}$. In addition, a calibration plot was established by addition of varying amounts of $\omega$-carboxy- $\mathrm{LTE}_{4}$ to a fixed amount of $6.75 \mathrm{ng}$ of $\left[{ }^{18} \mathrm{O}_{2}\right]-\omega$-carboxy-LTE ${ }_{4}$. Seven mixtures were prepared and derivatized as described, and the ratio of $\mathrm{m} / \mathrm{z}$ $609 / \mathrm{m} / z 613$ ranging from 0.04 to 3.7 was determined by negative ion CI-MS. A plot of this ratio ( $y$-axis) against the amount of $\omega$-carboxy-LTE $\mathrm{Ladded}_{4}(x$-axis) gave a straight line, with the regression equation $y=0.017+0.1482 x(R=1.00)$.

Quantification of urinary $\omega$-carboxy- $\mathrm{LTE}_{4}$ levels by isotope dilution using $\left[{ }^{18} \mathrm{O}_{2}\right]-\omega$-carboxy- $\mathrm{LTE}_{4}$ as internal standard gave the data displayed in Table II. All quantitative determinations were performed in triplicate, and the average standard deviations observed were $1.5 \%$ and $10.5 \%$ for the samples of the patients and of the control subjects, respectively. To illustrate the procedure, Fig. 3 gives two negative ion CI mass spectra, showing the analysis of a urine sample of a control subject
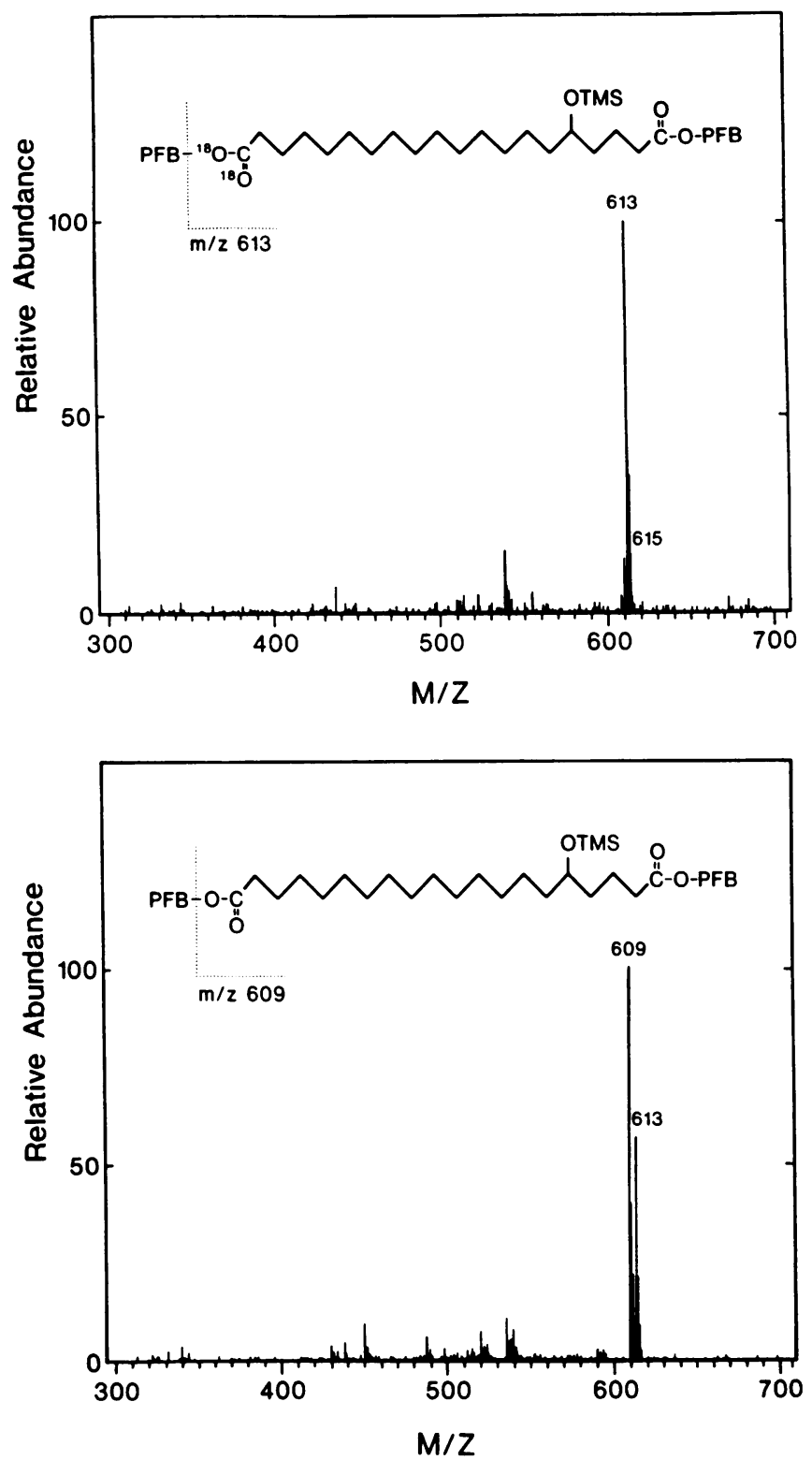

Figure 3. Mass spectrometric analysis of $\omega$-carboxy- $\mathrm{LTE}_{4}$ by negative ion chemical ionization. A $20-\mathrm{ml}$ sample of urine was spiked with $220 \mathrm{ng}$ of $\left[{ }^{18} \mathrm{O}_{2}\right] \omega$-carboxy-LTE $\mathrm{LE}_{4}$, and $\omega$-carboxy-LTE $\mathrm{LE}_{4}$ was separated by RP-HPLC, derivatized, and analyzed by GC-MS as described in Methods. Upper panel: control urine showing an intense signal for the ${ }^{18} \mathrm{O}$-labeled internal standard at $\mathrm{m} / \mathrm{z} 613$; lower panel: urine of patient 7 (Table I) with a concentration of $38 \mathrm{nM}$ of $\omega$-carboxy-LTE showing intense signals for sample and standard at $m / z 609$ and 613, respectively.

(upper panel) and the analysis of the urine of patient 7 (lower panel). The median of the $\omega$-carboxy- $\mathrm{LTE}_{4} /$ creatinine ratio in the patients is a factor of 68 in excess of the corresponding control level.

Quantification of $\omega$-carboxy-tetranor-LTE $E_{3}$. As shown in Table II, the $\beta$-oxidation product of $\omega$-carboxy- $-\mathrm{LTE}_{4}$, $\omega$-carboxy-tetranor-LTE ${ }_{3}$, was detectable by RIA exclusively in normal infants, but was below the detection limit in the patients.

Identification and quantification of $L T B_{4} . \mathrm{LTB}_{4}$ could be identified by GC-MS-MS in urine samples of patients as shown in Fig. 4 ( upper panel) but not of controls. The daughter ions at 

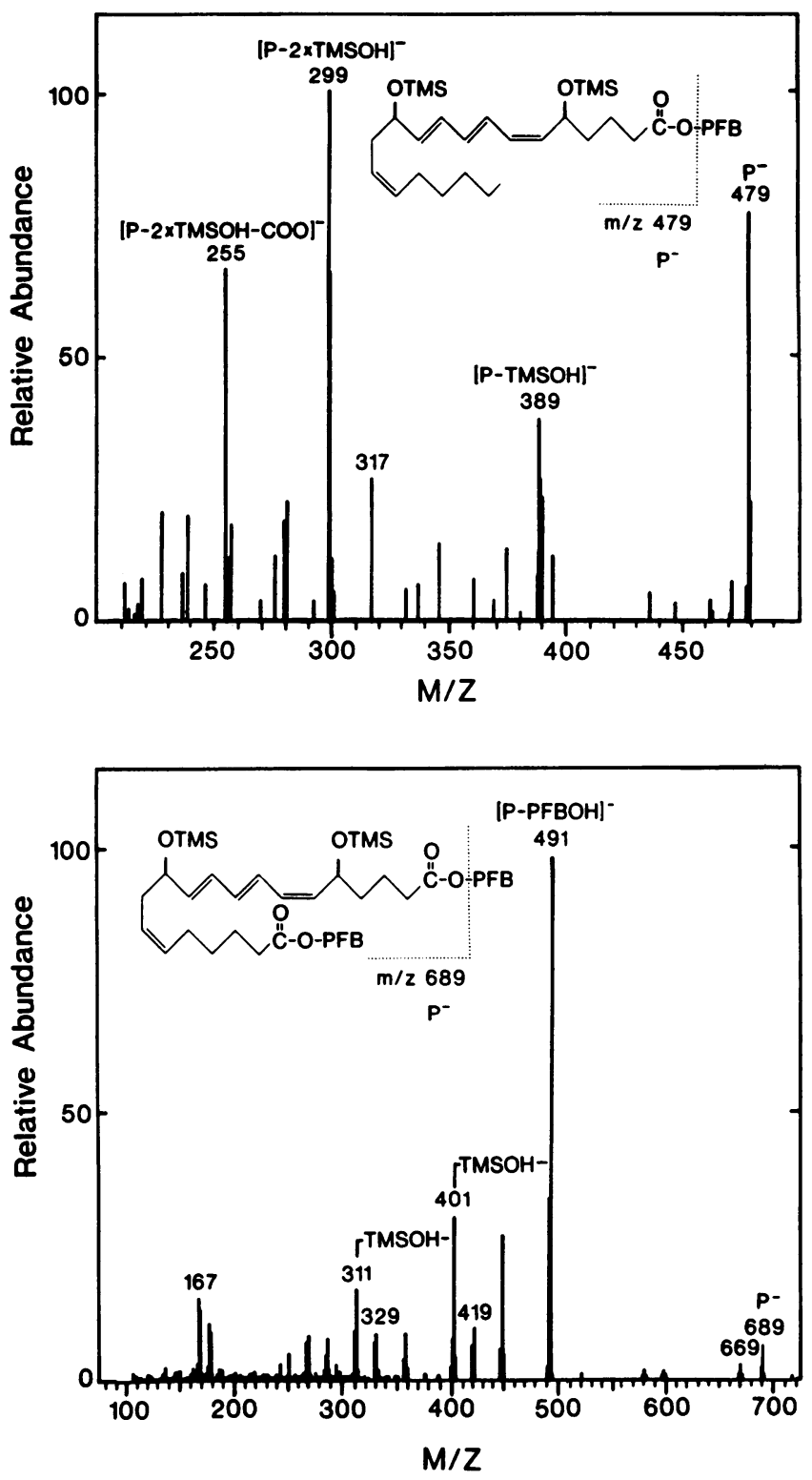

Figure 4. CAD mass spectra by GC-MS-MS analysis of the PFB ester/TMS ether derivatives of urinary $\mathrm{LTB}_{4}$ ( upper panel) and $\omega$-carboxy- $\mathrm{LTB}_{4}$ (lower panel) in patients with peroxisomal deficiency. The LT fractions were prepared as described in Methods. The mass spectra were generated by CAD of the corresponding [M-PFB] ${ }^{-}$(abbreviated as $\mathrm{P}^{-}$) parent ions which represent the base peaks in the corresponding negative ion $\mathrm{CI}$ mass spectra. These ions are found at $m / z 479$ for $\mathrm{LTB}_{4}$ and $m / z 689$ for $\omega$-carboxy-LTB 4 .

$m / z 389,299$, and 255 in the mass spectrum of the HPLC fraction with the retention time of $\left[{ }^{3} \mathrm{H}\right] \mathrm{LTB}_{4}$ (Fig. 4, upper panel) result from consecutive loss of one TMSOH group $(\mathrm{m} /$ $z$ 389), two TMSOH groups $(m / z 299)$, and two TMSOH groups plus $\mathrm{CO}_{2}(m / z 255)$ by CAD from the parent ion at $m / z$ 479. As shown in Table II, $\mathrm{LTB}_{4}$ could be quantified by RIA only in urine samples of the patients, whereas it was below the detection limit in the corresponding samples of the controls.

Identification of $\omega$-carboxy- $L T B_{4}$. In urine samples of all patients, the presence of $\omega$-carboxy- $\mathrm{LTB}_{4}$ was proven qualitatively by GC-MS-MS as shown in Fig. 4 (lower panel), whereas in all the samples of controls the corresponding signals were too weak to allow for identification. In the CAD mass spectrum of the PFB-TMS derivative from the HPLC peak with the reten-

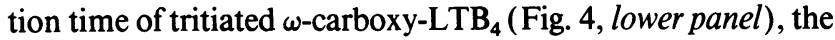
most prominent daughter ion was $m / z 491$ which results from loss of PFB alcohol from the parent ion at $m / z 689$ ([M$\left.\mathrm{PFB}]^{-}\right)$. Other characteristic ions were observed at $\mathrm{m} / z 401$ and 311 from consecutive loss of each TMSOH group from $m / z 491$ indicating two hydroxy groups.

\section{Discussion}

Peroxisome deficiency disorders, also termed disorders of peroxisome biogenesis, such as the Zellweger syndrome and neonatal adrenoleukodystrophy, are characterized by typical clinical features $(35,36)$ and by a specific set of biochemical abnormalities that include increased VLCFAs in plasma and fibroblasts (45), greatly elevated levels of intermediates of bile acid biosynthesis in plasma (46) and impaired de novo plasmalogen biosynthesis in fibroblasts (47). As shown in Table I, all these characteristic changes were found in the patients investigated in this study.

In vitro and in vivo studies have demonstrated that peroxisomes play a major role in the $\beta$-oxidation of LTs from the $\omega$-end (44). In peroxisome deficiency one would expect, therefore, as a consequence a lack of $\beta$-oxidation products of LTs in urine. The degradation product of $\mathrm{LTE}_{4}$ via $\beta$-oxidation, $\omega$-carboxy-tetranor-LTE ${ }_{3}$, has been identified as a urinary metabolite in the human (50). In the case of $\mathrm{LTB}_{4}, \omega$ - and $\beta$-oxidation products have never been detected in urine $(27)$ because of the extensive oxidative degradation of $\mathrm{LTB}_{4}(16,27)$. The mass spectra of the PFB-TMS derivatives of the compounds co-eluting with ${ }^{18} \mathrm{O}$-labeled $\omega$-carboxy-LTE ${ }_{4}$ and ${ }^{3} \mathrm{H}$-labeled $\omega$-carboxy-LTB $\mathrm{L}_{4}$, and $\mathrm{LTB}_{4}$, shown in Figs. 3 and 4, closely correspond to the ones obtained from the respective synthetic standards. This demonstrates unequivocally the presence of $\omega$-carboxy-LTE ${ }_{4}$, $\omega$-carboxy-LTB ${ }_{4}$, and $\mathrm{LTB}_{4}$ in urine of patients with peroxisome deficiency. The present study shows an altered pattern of LT metabolites in urine which is consistent with an impairment of peroxisomal LT degradation. It is in accordance with the metabolic block indicated in Fig. 1 that $\omega$-carboxy- $-\mathrm{LE}_{4}$ was excreted in large amounts in urine of the patients (Table II). The presence of $\omega$-carboxy-LTB $\mathrm{L}_{4}$ in patients' urine is of particular interest, because its degradation in isolated mitochondria has been shown to be an alternative route (44). In order to evaluate the importance of peroxisomes in humans with regard to the degradation of $\omega$-carboxy-LTB ${ }_{4}$, a normal mitochondrial function in these patients is a prerequisite. Abnormal structure and function of liver mitochondria have been described in some patients with Zellweger syndrome (33); although this is not a consistent finding in all patients (36). As shown in Table I, VLCFAs, which normally are oxidized in peroxisomes, accumulate in the patients. However, long chain fatty acids, which are mainly oxidized in mitochondria, did not accumulate. The latter results support the conclusion that the mitochondrial $\beta$-oxidation capacity was not impaired in our patients. In some of the patients listed in Table I, mitochondrial $\beta$-oxidation activity was assayed in cultured fibroblasts using $\left[1-{ }^{14} \mathrm{C}\right]$ palmitate and found to be in the range of normal subjects. Degradation of $\omega$-carboxy-LTB ${ }_{4}$ in mitochondria, therefore, seems to be insufficient or not functioning in the patients. Furthermore, it is consistent with the lack of 
peroxisomal $\beta$-oxidation in peroxisome deficiency (Fig. 1 ) that the $\beta$-oxidation product $\omega$-carboxy-tetranor- $\mathrm{LTE}_{3}$ was absent in all patient urines whereas this metabolite was detectable in normal infants, indicating an impairment of $\beta$-oxidation of $\omega$-carboxy-LTE $\mathrm{LE}_{4}$ in peroxisomal deficiency (Table II). Our results concerning impaired LT degradation and inactivation in peroxisomal deficiency together with the identification of peroxisomes as the site of LT degradation (44) contribute to the characterization of the functional role of peroxisomes in humans. In addition to the role of peroxisomes in the oxidation of VLCFAs ( 53) and bile acid precursors $(43,54-56)$, the organelle is involved in the chain-shortening of prostaglandins $E_{2}$ and $\mathrm{F}_{2 \alpha}$ from the $\mathrm{Cl}$-carboxy terminus (57-59) as well as in the degradation of dicarboxylic acids which are formed from long chain fatty acids via $\omega$-oxidation (60).

As an unexpected finding, both $\mathrm{LTE}_{4}$ and $\mathrm{LTB}_{4}$ were excreted in increased amounts in the urine of patients (Table II). There are no data to suggest that $\omega$-hydroxylation or conversion to $\omega$-carboxy-LTE $\mathrm{L}_{4}$ and $\omega$-carboxy- $\mathrm{LTB}_{4}$ are impaired in peroxisome deficiency. However, lipids other than leukotrienes, which are normally degraded in peroxisomes, such as prostaglandins (57-59) and VLCFAs (53), are expected to accumulate at manifold higher concentrations than the LTs. Such compounds may interfere with hepatocellular uptake and/or one or more of the enzymes involved in LT catabolism by $\omega$-hydroxylation, formation of the $\omega$-carboxy derivative, and coenzyme $A$ activation. At present, it cannot be decided whether competitive inhibition of one or more of these reactions leading from $\mathrm{LTE}_{4}$ and $\mathrm{LTB}_{4}$ to the respective substrates for peroxisomal $\beta$-oxidation is effective in peroxisome deficiency.

Urinary $\mathrm{LTE}_{4}$ concentration may be elevated due to an increase in systemic cysteinyl LT production (28-32). In addition to $\mathrm{LTE}_{4}$, the large amount of $\omega$-carboxy-LTE $\mathrm{LT}_{4}$ in urine suggests that there is an enhanced synthesis of cysteinyl LTs in the peroxisome deficient patients when compared to the matched control subjects. Impaired degradation and inactivation of LTs leading to nanomolar concentrations of these potent mediators ( Table II ) might be of pathophysiological significance in the course of the disease. $\mathrm{LTE}_{4}$ is biologically still active, whereas the corresponding $\omega$-oxidation product, $\omega$-carboxy-LTE $\mathrm{L}_{4}$ and its $\beta$-oxidized catabolites are biologically inactive (21). Although $\mathrm{LTE}_{4}$ is less active than $\mathrm{LTD}_{4}$ and $\mathrm{LTC}_{4}$ on a molar basis, it is still 10-100 times more active than histamine as a bronchoconstrictor in normal humans (61). Moreover, $\mathrm{LTE}_{4}$ promotes plasma extravasation at low nanomolar concentration (62). Elevated concentrations of biologically active LTs might contribute to symptoms like vascular leakage, oedema, mucus secretion, and smooth muscle contraction (2$4,6)$. $\omega$-Oxidation of $\mathrm{LTB}_{4}$ to $\omega$-carboxy-LTB ciated with a loss of biological activity, has been observed in neutrophils $(14,15,63)$ as well as in hepatocytes $(16,64)$. Furthermore, hepatocytes actively $\beta$-oxidize $\omega$-carboxy-LTB $\mathrm{LT}_{4}$ from the $\omega$-end $(16,44,65) \cdot\left[{ }^{3} \mathrm{H}\right] \mathrm{LTB}_{4}$ was almost completely degraded by $\omega$-oxidation and subsequent $\beta$-oxidation from $\omega$ end (27). Therefore, the presence of urinary $\omega$-carboxy-LTB found in all patients and the absence of this metabolite in normal infants indicate, analogous to $\omega$-carboxy- $\mathrm{LTE}_{4}$, an impairment of the degradation of this metabolite via $\beta$-oxidation in peroxisome deficiency. Moreover, the increased levels of $\mathrm{LTB}_{4}$ (Table II), one of the most powerful chemotactic substances (5), might be of pathophysiological significance.
Whereas increased urinary $\mathrm{LTE}_{4}$ and $N$-acetyl-LTE $\mathrm{L}_{4}$ occur under several pathophysiologic conditions (28-32), peroxisome deficiency is the first and so far only disorder with a pronounced urinary excretion of $\omega$-carboxy- $\mathrm{LTE}_{4}, \omega$-carboxy$\mathrm{LTB}_{4}$, and $\mathrm{LTB}_{4}$. The measurement of these metabolites, particularly in the absence of detectable amounts of urinary $\omega$-car-

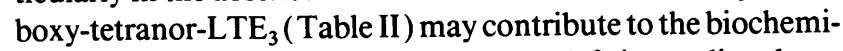
cal analyses for diagnosis of peroxisome deficiency disorders.

\section{Acknowledgments}

We are grateful to the following colleagues from hospitals in Germany for providing samples from patients with peroxisomal deficiencies: Dr. D. H. Hunneman and Dr. G.-C. Korenke (University of Göttingen), Dr. E. Reuter and Dr. T. Bösing (Children's Hospital, Bethel), Dr. K. Meyer-Feldmann (Münster), Dr. D. Bafteh (Wuppertal), and Dr. H.-D. Franke (Children's Hospital, Wolfsburg). We are indebted to Dr. A. W. Ford-Hutchinson (Merck Frosst, Canada) for providing the antibody against $\mathrm{LTB}_{4}$ and to Dr. P. Tagari (Merck Frosst, Canada) for

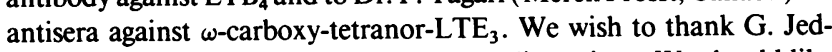
litschky for many helpful suggestions and discussions. We should like to thank U. Berger for her help in preparing the figures and Dr. M. Müller for his help in the purification of the antisera against $\omega$-carboxytetranor-LTE . .

This study was supported in part by the Deutsche Forschungsgemeinschaft, Bonn (Ma 1314/1-1), the Bundesministerium für Forschung und Technologie (01 VM 9002/0), and by the Fonds der Chemischen Industrie, Frankfurt, Germany.

\section{References}

1. Murphy, R. C., S. Hammarström, and B. Samuelsson. 1979. Leukotriene C: a slow-reacting substance from murine mastocytoma cells. Proc. Natl. Acad. Sci. USA. 76:4275-4279.

2. Hammarström, S. 1983. Leukotrienes. Annu. Rev. Biochem. 52:355-377.

3. Lewis, R. A., and K. F. Austen. 1984. The biologically active leukotrienes. J. Clin. Invest. 73:889-897.

4. Samuelsson, B., S.-E. Dahlén, J. A. Lindgren, C. A. Rouzer, and C. N. Serhan. 1987. Leukotrienes and lipoxins: structures, biosynthesis, and biological effects. Science (Wash. DC). 237:1171-1176.

5. Ford-Hutchinson, A. W. 1985. Leukotrienes: their formation and role as inflammatory mediators. Fed. Proc. 44:25-29.

6. Ford-Hutchinson, A. W. 1989. Evidence for the involvement of leukotrienes and other lipoxygenase products in disease states. In Leukotrienes and Lipoxygenases. Chemical, Biological and Clinical Aspects. J. Rokach, editor. Elsevier Science Publishing Co., Inc., New York. 405-425.

7. Keppler, D., M. Huber, T. Baumert, and A. Guhlmann. 1989. Metabolic inactivation of leukotrienes. Adv. Enzyme Regul. 28:307-319.

8. Hammarström, S., K. Bernström, L. Örning, S.-E. Dahlén, and P. Hedqvist. 1981. Rapid in vivo metabolism of leukotriene $C_{3}$ in the monkey, Macaca irus. Biochem. Biophys. Res. Commun. 101:1109-1115.

9. Huber, M., and D. Keppler. 1987. Inhibition of leukotriene $\mathrm{D}_{4}$ catabolism by D-penicillamine. Eur. J. Biochem. 167:73-79.

10. Appelgren, L.-E., and S. Hammarström. 1982. Distribution and metabolism of ${ }^{3} \mathrm{H}$-labeled leukotriene $\mathrm{C}_{3}$ in the mouse. J. Biol. Chem. 257:531-535.

11. Hagmann, W., C. Denzlinger, and D. Keppler. 1984. Role of peptide leukotrienes and their hepatobiliary elimination in endotoxin action. Circ. Shock. 14:223-235.

12. Keppler, D., W. Hagmann, S. Rapp, C. Denzlinger, and H. K. Koch. 1985. The relation of leukotrienes to liver injury. Hepatology. 5:883-891.

13. Hagmann, W., and M. Korte. 1990. Hepatic uptake and metabolic disposition of leukotriene $B_{4}$ in rats. Biochem. J. 267:467-470.

14. Hansson, G., J.-A. Lindgren, S. E. Dahlén, P. Hedqvist, and B. Samuelsson. 1981. Identification and biological activity of novel omega-oxidized metabolites of leukotriene $\mathrm{B}_{4}$ from human leukocytes. FEBS (Fed. Eur. Biol. Soc.) Lett. 130:107-112.

15. Shak, S., and I. M. Goldstein. 1984. $\omega$-Oxidation is the major pathway for the catabolism of leukotriene $\mathrm{B}_{\mathbf{4}}$ in human polymorphonuclear leukocytes. $J$. Biol. Chem. 259:10181-10187.

16. Harper, T. W., M. J. Garrity, and R. C. Murphy. 1986. Metabolism of leukotriene $B_{4}$ in isolated rat hepatocytes: Identification of a novel 18-carboxy19,20-dinor leukotriene $B_{4}$ metabolite. J. Biol. Chem. 261:5414-5418. 
17. Örning, L. 1987. $\omega$-Oxidation of cysteine-containing leukotrienes by rat liver microsomes. Isolation and characterization of $\omega$-hydroxy and $\omega$-carboxy metabolites of leukotriene $\mathrm{E}_{4}$ and $\mathrm{N}$-acetylleukotriene $\mathrm{E}_{4}$. Eur. J. Biochem. 170:77-85

18. Ball, H. A., and D. Keppler. 1987. $\omega$-Oxidation products of leukotriene $\mathrm{E}_{4}$ in bile and urine of the monkey. Biochem. Biophys. Res. Commun. 148:664-670.

19. Foster, A., B. Fitzsimmons, J. Rokach, and G. Letts. 1987. Evidence of in-vivo $\omega$-oxidation of peptide leukotrienes in the rat: biliary excretion of 20 -

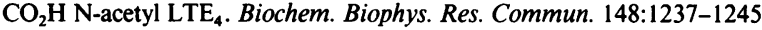

20. Stene, D. O., and R. C. Murphy. 1988. Metabolism of leukotriene $E_{4}$ in isolated rat hepatocytes. Identification of $\beta$-oxidation products of sulfidopeptide leukotrienes. J. Biol. Chem. 263:2773-2778.

21. Samhoun, M. N., D. M. Conroy, P. J. Piper. 1989. Pharmacological profile of leukotriene $\mathrm{E}_{4}, \mathrm{~N}$-acetyl $\mathrm{E}_{4}$ and four of their novel $\omega$ - and $\beta$-oxidative metabolites in airways of guinea pig and man in vitro. Br. J. Pharmacol. 98:14061412.

22. Maltby, N. H., G. W. Taylor, J. M. Ritter, K. Moore, R. W. Fuller, and C. T. Dollery. 1990. Leukotriene $\mathrm{C}_{4}$ elimination and metabolism in man. $J$. Allergy Clin. Immunol. 85:3-9.

23. Huber, M., J. Müller, I. Leier, G. Jedlitschky, H. A. Ball, K. P. Moore, G. W. Taylor, R. Williams, and D. Keppler. 1990. Metabolism of cysteinyl leukotrienes in monkey and man. Eur. J. Biochem. 194:309-315.

24. Sala, A., N. Voelkel, J. Maclouf, and R. C. Murphy. 1990. Leukotriene $E_{4}$ elimination and metabolism in normal human subjects. J. Biol. Chem. 265:21771-21778.

25. Örning, L., L. Kaijser, and S. Hammarström. 1985. In vivo metabolism of leukotriene $\mathrm{C}_{4}$ in man: urinary excretion of leukotriene $\mathrm{E}_{4}$. Biochem. Biophys. Res. Commun. 130:214-220.

26. Denzlinger, C., A. Guhlmann, P. H. Scheuber, D. Wilker, D. K. Hammer, and D. Keppler. 1986. Metabolism and analysis of cysteinyl leukotrienes in the monkey. J. Biol. Chem. 26:15601-15606.

27. Serafin, W. E., J. A. Oates, and W. C. Hubbard. 1984. Metabolism of leukotriene $\mathrm{B}_{4}$ in the monkey. Identification of the principal nonvolatile metabolite in the urine. Prostaglandins. 27:899-911.

28. Keppler, D., M. Huber, W. Hagmann, H. A. Ball, A. Guhlmann, and S. Kästner. 1988. Metabolism and analysis of endogenous cysteinyl leukotrienes. Ann. N.Y. Acad. Sci. 524:68-74.

29. Tagari, P., D. Ethier, M. Carry, V. Korley, S. Charleson, Y. Girard, and R. Zamboni. 1989. Measurement of urinary leukotrienes by reversed-phase liquid chromatography and radioimmunoassay. Clin. Chem. 35:388-391.

30. Taylor, G. W., I. Taylor, P. Black, N. H. Maltby, N. Turner, R. W. Fuller, and C. T. Dollery. 1989. Urinary leukotriene $E_{4}$ after antigen challenge in acute asthma and allergic rhinitis. Lancet. $i: 584-588$.

31. Huber, M., S. Kästner, J. Schölmerich, W. Gerok, and D. Keppler. 1989 Analysis of cysteinyl leukotrienes in human urine: enhanced excretion in patients with liver cirrhosis and hepatorenal syndrome. Eur. J. Clin. Invest. 19:53-60.

32. Fauler, J., D. Tsikas, M. Holch, A. Seekamp, M. L. Nerlich, J. Sturm, and J. C. Frölich. 1991. Enhanced urinary excretion of leukotriene $E_{4}$ by patients with multiple trauma with or without respiratory distress syndrome. Clin. Sci. 80:497504.

33. Goldfischer, S., C. L. Moore, A. B. Johnson, A. J. Spiro, M. P. Yalsamis, H. K. Wisniewski, R. H. Ritch, W. T. Norton, I. Rapin, and L. M. Gartner. 1973. Peroxisomal and mitochondrial defects in the cerebrohepatorenal syndrome. Science (Wash. DC). 182:62-64.

34. Bowen, P., C. N. S. Lee, H. Zellweger, and H. Lindenberg. 1964. A familial syndrome of multiple congenital defects. Bull. Johns Hopkins Hosp. 114:402414.

35. Kelley, R. I. 1983. Review: the cerebrohepatorenal syndrome of Zellweger, morphologic and metabolic aspects. Am. J. Med. Genet. 16:503-517.

36. Lazarow, P., and H. W. Moser. 1989. Disorders of peroxisome biogenesis In The Metabolic Basis of Inherited Disease. 6th edition. C. R. Scriver, A. L. Beaudet, W. S. Sly, and D. Valle, editors. McGraw-Hill, Inc., New York. $1497-$ 1509.

37. Moser, A. E., I. Singh, F. R. Brown, G. I. Solish, R. I. Kelley, P. J. Benke, and H. W. Moser. 1984. The cerebro-hepato-renal (Zellweger) syndrome: increased levels and impaired degradation of very long chain fatty acids and their use in prenatal diagnosis. $N$. Engl. J. Med. 310:1141-1146.

38. Poulos, A., P. Sharp, and M. Whiting. 1984. Infantile Refsum's disease (phytanic acid storage disease): a variant of Zellweger syndrome? Clin. Genet 26:579-586

39. Stokke, O., S. Skrede, J. Ek, and I. Björkhem. 1984. Refsum's disease, adrenoleukodystrophy, and the Zellweger syndrome. Scand. J. Clin. Lab. Invest 44:463-464

40. Danks, D. M., P. Tippett, C. Adams, and P. Campell. 1975. Cerebro-hepato-renal syndrome of Zellweger: a report of eight cases with comments upon the incidence, the liver lesion, and a fault in pipecolic acid metabolism. J. Pediatr $86: 382-387$

41. Heymans, H. S. A., R. B. H. Schutgens, R. Tan, H. van den Bosch, and P. Borst. 1983. Severe plasmalogen deficiency in tissues of infants without peroxisomes (Zellweger syndrome). Nature (Lond.). 306:69-70.
42. Monnens, L., J. Bakkeren, G. Parmetier, G. Janssen, $U$, van Haelst, F. Trijbels, and H. Eyssen. 1980. Disturbances in bile acid metabolism of infants with the Zellweger (cerebro-hepato-renal) syndrome. Eur. J. Pediatr. 133:31-35.

43. Kase, B. F., J. I. Pedersen, B. Strandvick, and I. Björkhem. 1985. In vivo and in vitro studies on the formation of bile acids in patients with Zellweger syndrome: evidence that peroxisomes are of importance in the normal biosynthesis of both cholic and chenodeoxycholic acid. J. Clin. Invest. 76:2393-2402.

44. Jedlitschky, G., M. Huber, A. Völkl, M. Müller, I. Leier, J. Müller, W.-D. Lehmann, H. D. Fahimi, and D. Keppler. 1991. Peroxisomal degradation of leukotrienes by $\beta$-oxidation from the $\omega$-end. J. Biol. Chem. 266:24763-24772.

45. Wanders, R. J. A., M. J. A. van Wijland, C. W. T. van Roermund, R. B. H. Schutgens, H. van den Bosch, J. M. Tager, A. Nijenhuis, and A. Tromp. 1987. Prenatal diagnosis of Zellweger syndrome by measurement of VLCFA (C26:0) $\beta$-oxidation in cultured chorionic villous fibroblasts. Clin. Chim. Acta. 165:303310 .

46. Eldere van, J. B., G. G. Parmentier, H. J. Eyssen, R. J. Wanders, R. B. Schutgens, J. Vamecq, F. van Hoof, B.-T. Poll-Thé, and J.-M. Saudubray. 1987. Bile acids in peroxisomal disorders. Eur. J. Clin. Invest. 17:386-390.

47. Schrakamp, G., C. G. Schalkwijk, R. B. H. Schutgens, R. J. A. Wanders, J. M. Tager, and H. van den Bosch. 1988. Plasmalogen biosynthesis in peroxisomal disorders. J. Lipid Res. 29:325-334.

48. Hagmann, W., C. Denzlinger, S. Rapp, G. Weckbecker, and D. Keppler. 1986. Identification of the major leukotriene metabolite in the bile of rats as $\mathrm{N}$-acetyl-leukotriene $\mathrm{E}_{4}$. Prostaglandins. 31:239-251.

49. Guhlmann, A., A. Keppler, S. Kästner, H. Krieter, U. B. Brückner, K. Messmer, and D. Keppler. 1989. Prevention of endogenous leukotriene production during anaphylaxis in the guinea pig by an inhibitor of leukotriene biosynthesis (MK-886) but not by dexamethasone. J. Exp. Med. 170:1905-1918.

50. Tagari, P., J. B. Rasmussen, D. Delorme, Y. Girard, L.-O. Eriksson, S Charleson, and A. W. Ford-Hutchinson. 1990. Comparison of urinary leukotriene $\mathrm{E}_{4}$ and 16-carboxy-tetranordihydro-leukotriene $\mathrm{E}_{4}$ excretion in allergic asthmatics after inhaled antigen. Eicosanoids. 3:75-80.

51. Balazy, M., and R. C. Murphy. 1986. Determination of sulfidopeptide leukotrienes in biological fluids by gas chromatography/mass spectrometry. Anal. Chem. 58:1098-1101.

52. Jedlitschky, G., I. Leier, M. Huber, and D. Keppler. 1990. Inhibition of leukotriene $\omega$-oxidation by $\omega$-trifluoro analogs of leukotrienes. Arch. Biochem Biophys. 282:333-339.

53. Singh, I., A. E. Moser, S. Goldfischer, and H. W. Moser. 1984. Lignoric acid is oxidized in the peroxisomes: implications for the Zellweger cerebro-hepato-renal syndrome and adrenoleukodystrophy. Proc. Natl. Acad. Sci. USA 81:4203-4207.

54. Pedersen, J. I., and J. Gustafsson. 1980. Conversion of $3 \alpha, 7 \alpha, 12 \alpha-$ trihydroxy-5 $\beta$-cholestanoic acid into cholic acid by rat liver peroxisomes. FEBS (Fed. Eur. Biol. Soc.) Lett. 121:345-348.

55. Kase, B. F., I. Björkhem, and J. I. Pedersen. 1983. Formation of cholic acid from $3 \alpha, 7 \alpha, 12 \alpha$-trihydroxy-5 $\beta$-cholestanoic acid by rat liver peroxisomes. J. Lipid Res. 24:1560-1567.

56. Kase, B. F., I. Björkhem, P. Haga, and J. I. Pedersen. 1985. Defective peroxisomal cleavage of the $\mathrm{C}_{27}$-steroid side chain in the cerebro-hepato-renal syndrome of Zellweger. J. Clin. Invest. 75:427-435.

57. Diczfalusy, U., S. E. H. Alexson, and J. I. Pedersen. 1987. Chain-shortening of prostaglandin $\mathrm{F}_{2 \alpha}$ by rat liver peroxisomes. Biochem. Biophys. Res. Commun. 144:1206-1215.

58. Schepers, L., M. Casteels, J. Vameca, G. Parmentier, P. P. van Veldhoven, and G. P. Mannaerts. 1989. $\beta$-Oxidation of the carboxy side chain of prostaglan$\operatorname{din} E_{2}$ in rat liver peroxisomes and mitochondria. J. Biol. Chem. 263:2724-2731.

59. Diczfalusy, U., B. F. Kase, S. E. H. Alexson, and I. Björkhem. 1991. Metabolism of prostaglandin $F_{2 \alpha}$ in Zellweger syndrome: peroxisomal $\beta$-oxidation is of major importance for in vivo degradation of prostaglandins in humans. J. Clin. Invest. 88:978-984.

60. Vamecq, J., and J.-P. Draye. 1987. Interaction between the $\omega$ - and $\beta$-oxidation of fatty acids. J. Biochem. 102:225-234.

61. Barnes, N. C., and P. J. Piper. 1986. The actions of leukotrienes in human lung in vitro and in vivo. In The Leukotrienes: Their Biological Significance. P. J. Piper, editor. Raven Press, New York. 199-212.

62. Hua, C.-Y., S.-E. Dahlén, J. M. Lundberg, S. Hammarström, and P. Hedqvist. 1985. Leukotriene $C_{4}, D_{4}$ and $E_{4}$ cause widespread and extensive plasma extravasation in the guinea pig. Naunyn-Schmiedeberg's Arch. Pharmacol. 330:136-141.

63. Soberman, R. J., J. P. Sutyak, R. T. Okita, D. F. Wendelborn, L. J. Roberts, II, and K. F. Austen. 1988. The identification and formation of 20-aldehyde leukotriene $B_{4}$. J. Biol. Chem. 263:7996-8002.

64. Baumert, T., M. Huber, D. Mayer, and D. Keppler. 1989. Ethanol-induced inhibition of leukotriene degradation by $\omega$-oxidation. Eur. J. Biochem. 182:223-229.

65. Shirley, M. A., and R. C. Murphy. 1990 . Metabolism of leukotriene $B_{4}$ in isolated rat hepatocytes: involvement of 2,4-dienoyl-coenzyme A reductase in leukotriene $\mathrm{B}_{4}$ metabolism. J. Biol. Chem. 265:16288-16295. 